by interannual changes in soil moisture and snow cover over continents.

A very different explanation for the irregular period between El Niño events invokes the long memory of the ocean as the principal source of perturbations ${ }^{14-21}$, assigning random atmospheric perturbations a minor role. In this model, the oceanic response to wind variations during El Niño does not end when the event ends but continues in the form of waves that slowly propagate westwards in off-equatorial latitudes. On reaching the western boundary of the ocean basin the waves give rise to renewed equatorial disturbances which, through unstable airsea interactions, again amplify into a new El Niño. The interval between El Niño events is essentially the transit time of the waves, which in models of this type is of the order of three to four years. Some of the models ${ }^{19.21}$ are very periodic, but that of Cane and Zebiak ${ }^{21}$ is like an irregular nonlinear oscillator and produces timeseries almost as aperiodic as those which are observed. But fluctuations with periods less than that of the seasonal cycle are far less energetic in the model than in reality because processes other than airsea interactions that contribute to atmospheric variability are not considered.

The experimental predictions reported in this issue by Cane, Zebiak, and Dolan ${ }^{8}$ indicate that the atmospheric perturbations that are neglected in their model can cause predictions to diverge significantly after approximately one year. This is shorter than the timescale for the memory of the ocean (the waves) to initiate another event and suggests that the memory is not the dominant factor in determining the interval between El Niño events. The memory nonetheless is important in determining the predictability of the tropical oceans and atmospheres because it predisposes the ocean to behave in a certain manner. For a particular

1. Rasmusson, E.M. \& Wallace, J.M. Science 222, 1195 (1983).

Philander, S.G.H. Nature 302, 215 (1983)

Gill. A.E \& Rasmusson. E.M Nature 305.229(1983)

Barber, R.T. \& Chavez, F.P. Science 222, 1203 (1983)

5. Barber, R.T. \& Chavez, F.P. Science 222, 1203 (1983). Schreiber
(1983).

6arnett. T.P. Mon. Weath. Rev. 112, 1403 (1984).

Inoue. M. \& O'Brien, J.J. Mon. Weath. Rev. 112, 2326 (1984).

8. Cane, M.A. \& Zebiak. S.E. \& Dolan. Nature 321, 827 (1986).

9. Wyrtki, K J phys. Oceanogr 5, 572 (1985)

10. Philander, S.G.H. \& Seigal, A.D. in Coupled Ocean Atmosphere Models (ed. Nihoul, J.) 517 (Elsevier. Amsterdam, 1985)

11. Lau. N.-C. Mon. Weath. Rev. 113. 1970 (1985).

12. Boer. G.J. in Coupled Ocean-Aimosphere Models (ed Nihoul, J.) (Elsevier, Amsterdam, 1985).

13. Philander, S.G.H.\& Yamagata, T. \& Pacanowski. R.C. J atmos. Sci. 41, 604 (1984)

14. Gill, A.E. in Coupled Ocean-Atmosphere Models (ed Nihoul, J.) 303 (Elsevier, Amsterdam. 1985).

5. Hirst, A. J. atmos. Sci. 43, 606 (1986).

6. Bjerknes, J. Mon. Weath. Rev. 97. 163 (1969).

7. Philander. S.G.H. J. atmos. Sci. 42, 2652 (1985)

18. Lau. K.-M. J. atmos. Sci. 42. 1552 (1985).

19. McCreary. J.P. Mon. Weath. Rev. 111. 370 (1983).

20. Anderson. D.L.T. \& McCreary. J.P. J. atmos. Sci. 42.615 (1985).

21. Cane. M.A. \& Zebiak. S.E. Science 228. 1085 (1985). model, the behaviour of the ocean at a certain time can be determined by keeping the winds constant from that time onwards: if the ocean is not in equilibrium with the winds then it has a memory of earlier wind variations and continues to adjust. Inoue and O'Brien ' find that if their model is forced with realistic winds up to April 1982 then El Niño starts to develop during the subsequent months even if the winds are held constant. In other words, the non-equilibrium state of the ocean in early 1982 predisposed it towards the development of El Niño.

The coupled air-sea model of Cane, Zebiak and Dolan ${ }^{8}$ simulates the air-sea interactions that amplify the oceanic tendency associated with its non-equilibrium state to provide a forecast of El Niño almost a year in advance. The predictability of the model is limited by its neglect of atmospheric disturbances not attributable to air-sea interactions. These disturbances are particularly important when the ocean is in equilibrium with the prevailing winds and could mean that the prediction of an El Niño for 1986 is inaccurate. (Early in 1986, sea-surface temperatures in the eastern tropical Pacific Ocean were exceptionally high and El Niño appeared imminent. In mid-March the temperatures started to decrease and in May conditions looked essentially normal.) Reliable predictions require not only improved models of air-sea interactions but also a better understanding of and an ability to simulate the high-frequency atmospheric fluctuations.

S. G.H. Philander is in the National Oceanic and Atmospheric Adminstration/Geophysical Fluid Dynamics Laboratory, Princeton University, Princeton, New Jersey 08542, USA.

\title{
Acid rain
}

\section{Predictions and applications}

\section{from Nurtan A. Esmen}

ACID rain, a controversial phenomenon which has attracted much recent attention, has nevertheless been ignored by many scientists who are interested in fundamental transport processes. Hence, experimental and theoretical studies of rain acidification have been more or less repetitious, albeit in different locations. Although some rigorous theoretical work has been done in the past decade, field verification of theoretical results has been at best incomplete. This scarcity results from the difficulties associated in measuring simultaneously the size and the acidity of raindrops using the conventional instruments of aerosol physics or meteorology. A new instrumental development reported by S.J. Adams et al. elsewhere in this issue (Nature 321, 842; 1986), and the authors' preliminary measurements of raindrop acidity using the instrument, is good news for those interested in the problem of acid rain.

The new instrument, although ingenious, would be of limited interest if it were to apply only to one narrow area of research. Because the instrument, described in fuller detail elsewhere (Bradley, S.G.J. Tech. 2, 190; 1985), can obtain good results under non-ideal conditions, it will be of interest in, for example, agricultural research on effective watering systems, chemical engineering and combustion equipment design.

The preliminary results of droplet sizedependent rain acidity reported by Adams et al. are intriguing. Besides the fact that they are the only such measurements that exist, and that they seem to verify qualitatively an existing theory of steady-state raindrop-gaseous pollutant interactions, they also point to significant gaps in our understanding of both local and global influences on rainwater acidity. If the experimental results of Adams et al. are found in other sites, several hypotheses could be generated. For example, strong dependence of removal efficiency on raindrop size suggest that interactions between the mainly small drops of a drizzle and acid-producing gases such as sulphur dioxide would have significantly different consequences compared with the interaction between the same gas and the mainly large drops of a rain shower. Such an observation, if verified in different circumstances, opens up new areas of research into the effects of acid rain.

The results of Adams et al. also suggest that throughout a period of rainfall there is significant depletion of the local pollutant concentration. Thus, extended measurements using their new method may uncover a relationship between the variables of rain, in-cloud removal and below-cloud removal of contaiminants. If such a relationship is found, past and new data can be corrected to factor-out local influences, allowing global transport of contaminants to be reanalysed on a uniform basis. Although we have a fairly good grasp of large-scale transport, important details are still missing and the predictive capacity of the available models is limited. The accident at the nuclear reactor at Chernobyl in the Soviet Union provides an example of the use to which such models, if accurate, could be put. $\square$

Nurtan A. Esmen is Professor of Industrial Environmental Health Science at the Graduate School of Public Health. University of Pittsburgh, Pennsvlvania 15261, USA. 